\title{
Final Report - A High Intensity Multi-Purpose D-D Neutron Generator for Nuclear Engineering Laboratories
}

DOE Project DE-FG07-041D14606

Principle Investigator: Ka-Ngo Leung

Co-Investigators: Jasmina L. Vujic

Edward C. Morse

Per F. Peterson

PI/Co-PI's Affiliation: Department of Nuclear Engineering, University of California at Berkeley

\section{Students:}

Lili Ji, Nuclear Engineering, University of California at Berkeley Ye Chen, Nuclear Engineering, University of California at Berkeley

Report Period: September 1, 2004 - August 31, 2005

\section{Project Summary}

Goal - This NEER project involves the design, construction and testing of a low-cost high intensity D-D neutron generator for teaching nuclear engineering students in a laboratory environment without radioisotopes or a nuclear reactor. The neutron generator was designed, fabricated and tested at Lawrence Berkeley National Laboratory (LBNL).

This project was conducted in one phase with five tasks. Summaries of tasks and associated results are given below.

\section{Summary of Objectives}

\section{Task 1: Neutron generator design}

The design of the acquired neutron generator is taken from the latest in series of D-D neutron generators developed at Lawrence Berkeley National Laboratory during the last ten years. It has several improvements over the original proposed sectioned insulator neutron generator design contributed by students and scientists at Plasma and Ion Source Technology Group at LBNL. Main improvements include the new ground shielded construction, which shields the high voltage target with a grounded vacuum chamber, and the simplified, single gap acceleration system for reliable high voltage operation of the neutron generator. 
The main features of this neutron generator are its ability to generate high neutron yields reliably with D-D fusion reaction, extremely long life time ion source design and sealed high voltage target design. The RF-induction based ion source has proven to be a long life-time and stable in operation. Figure 1 shows a cut-away view of the neutron generator with its ion source on the left. The ion source chamber is made of $\mathrm{Al}_{3} \mathrm{O}_{2}$ and it is actively cooled by water. The plasma is generated by the external RF-induction coil wrapped around the alumina ion source chamber. The deuterium gas is ionized in the ion source by exciting the electrons in the plasma with induced high frequency electromagnetic field. The RF-frequency used in the ion source is $13.56 \mathrm{MHz}$, which is the frequency used widely in various commercial applications. The RF-induction discharge generates high atomic species fraction which increases the overall power efficiency of the generator. At the same time it generates large volume plasma with high degree of uniformity in plasma density across the ion beam extraction.

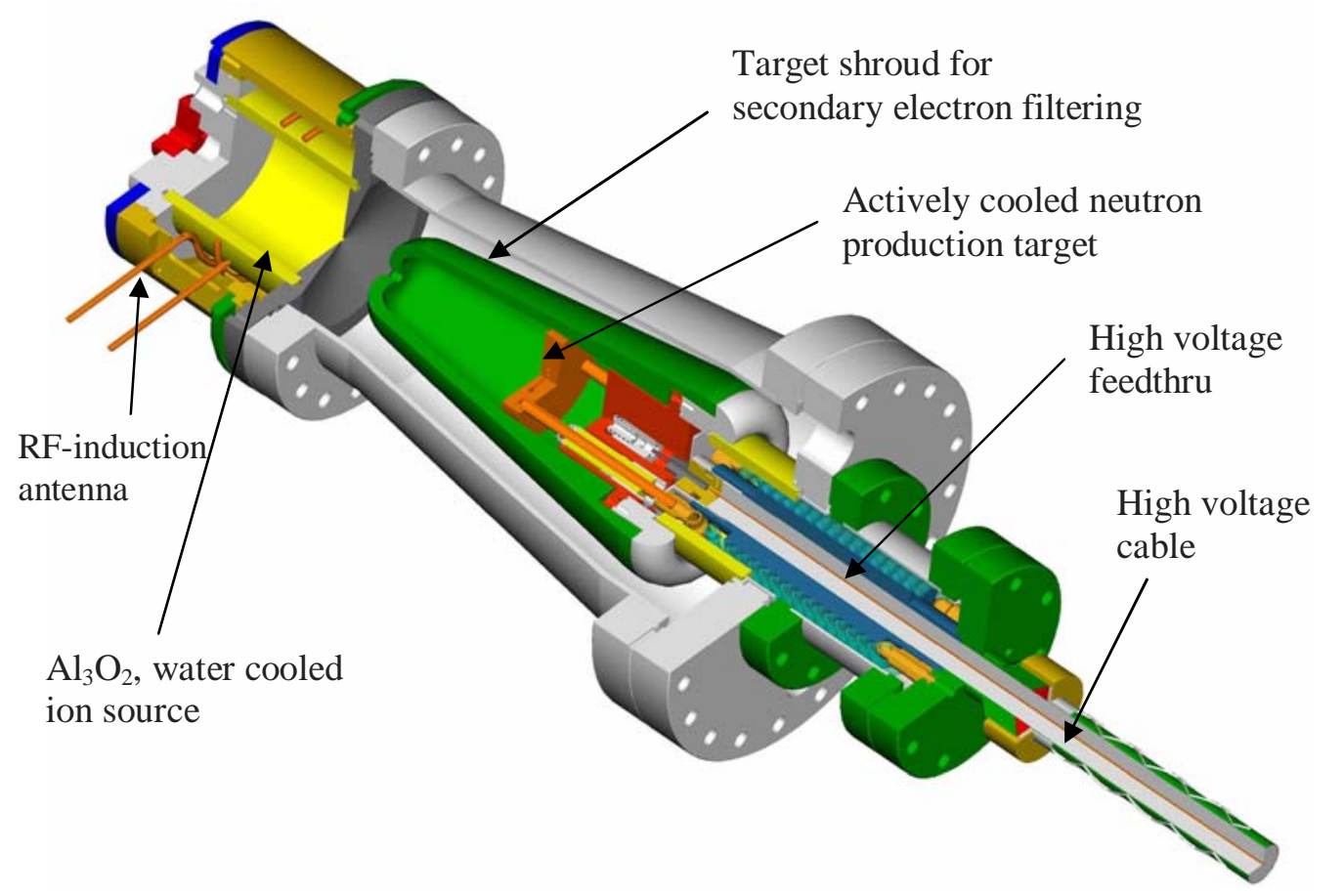

Figure 1 CAD drawing of the acquired neutron generator

The uniformity of plasma density across the ion beam extraction allows for high intensity ion beam extraction and very predictable beam behavior in the acceleration gap and in the drift section towards the target. It thus enables one to simulate the beam behavior accurately is the accelerator gap and in the drift section inside the target shroud. The RFamplifier was purchased from a commercial vendor.

The neutron production target is an explosive bonded titanium on copper and it is actively cooled with water. The target is surrounded by a biased shroud-electrode to prevent the secondary electrons back-streaming from the target. The biasing is done using a Zenerdiode to bias the target slightly (few hundred volts) more positive potential, compared to the target. 
The target/shroud structure is positioned within the vacuum boundaries of the neutron generator. This enhances both the reliability of the neutron generator operation regardless of the surrounding materials and the overall safety of the operation of the generator.

\section{Task 2: Components fabrication and assembly}

The axial neutron generator is designed and fabricated (with exception of the main vacuum vessel) in the Plasma and Ion Source Technology Group. The ion source alumina cylinder is purchased from Coors Tech Inc. and the explosive bonded titanium on copper is made by Atlas Technology Inc.

The neutron generator assembly is made of three main components: ion source, vacuum vessel and the target assembly. Ion source is made of the alumina cylinder with wraparound RF-antenna, see Figure 2. This internal assembly is sealed with o-rings with the front and back plates. The gas- and the pressure measurement feed-throughs are placed in the back plate. The front plate is also the water-cooled plasma electrode with the extraction aperture.

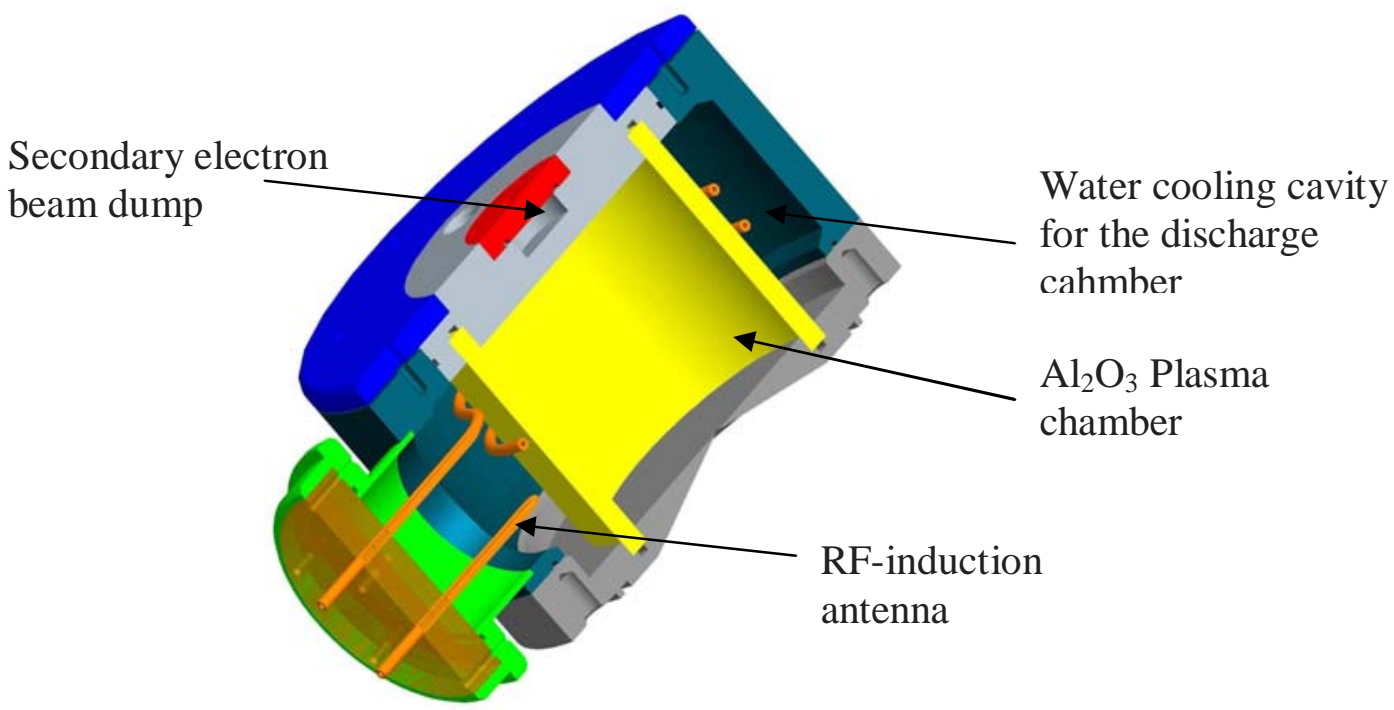

Figure 2. RF-induction ion source. The plasma is excited in the $\mathrm{Al}_{2} \mathrm{O}_{3}$ cylinder by the induced electromagnetic field of the RF-antenna.

The vacuum vessel is a tapered stainless steel tube, where the 8 " cf-flange is welded for the ion source and 10" cf-flange is welded for the target assembly. It also houses the $23 / 4$ " cf-flange for the pumping system. The target assembly (see Figure 3.) is made of a brazed alumina insulator cylinder, target and the high voltage feed-through section with the Zener-diode and target cooling. The high voltage shroud is attached to the target assembly by using threaded attachment. The high voltage holding is further enhanced by filling the high voltage feed-through with transformer oil. Water cooling lines are 
attached using a standard push-on fitting from Legris. This ion source and the target assembly are bolted to the vacuum vessel flanges using o-ring seal (ion source) or copper gasket (the target assembly).

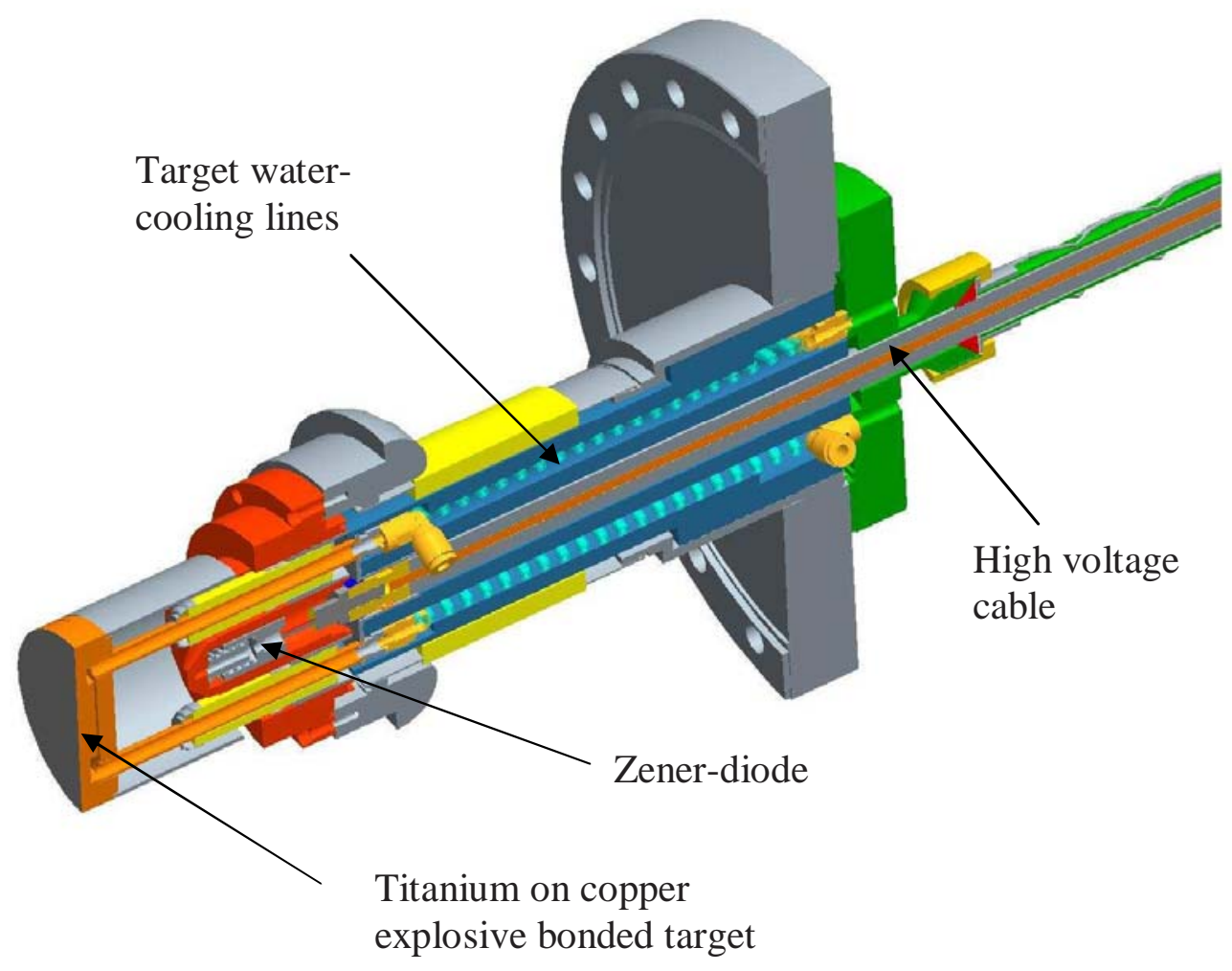

Figure 3. Target assembly and the transformer oil filled high voltage cable feedtrhrough.

\section{Task 3: Neutron generator performance testing}

The ion source was tested separately from the accelerator section for the extracted ion current density and the hydrogen species distribution. See Figure 4 for a current density measurement and Figure 5 for species measurement of the source. 


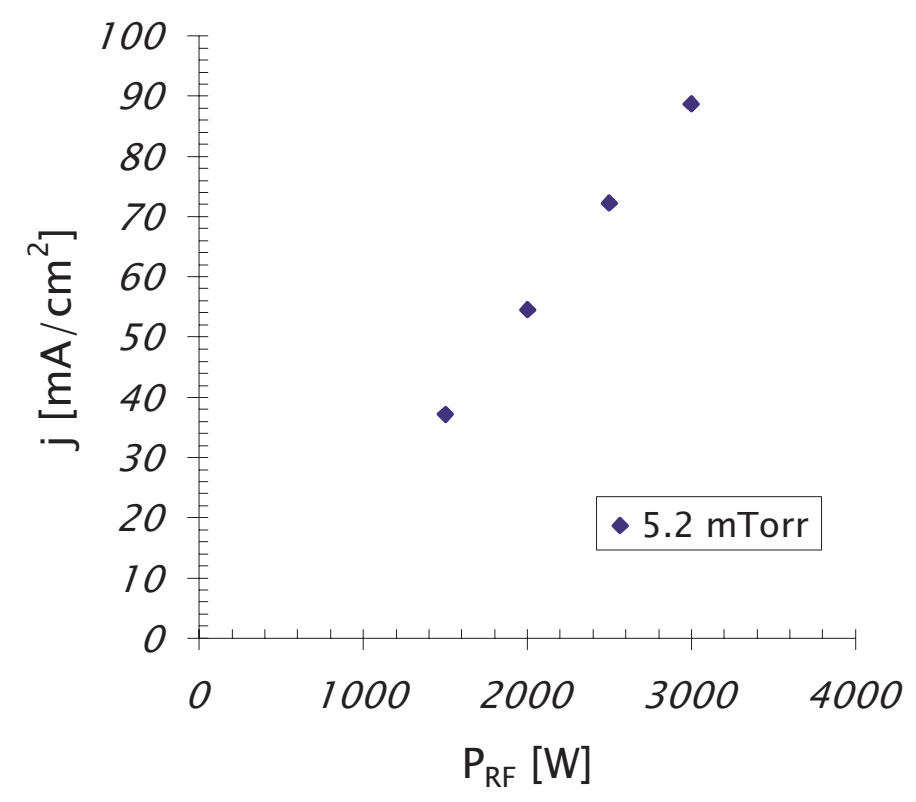

Figure 4. Extracted current density of the water-cooled, RF-induction ion source at the current saturation point as a function of RF-discharge power.

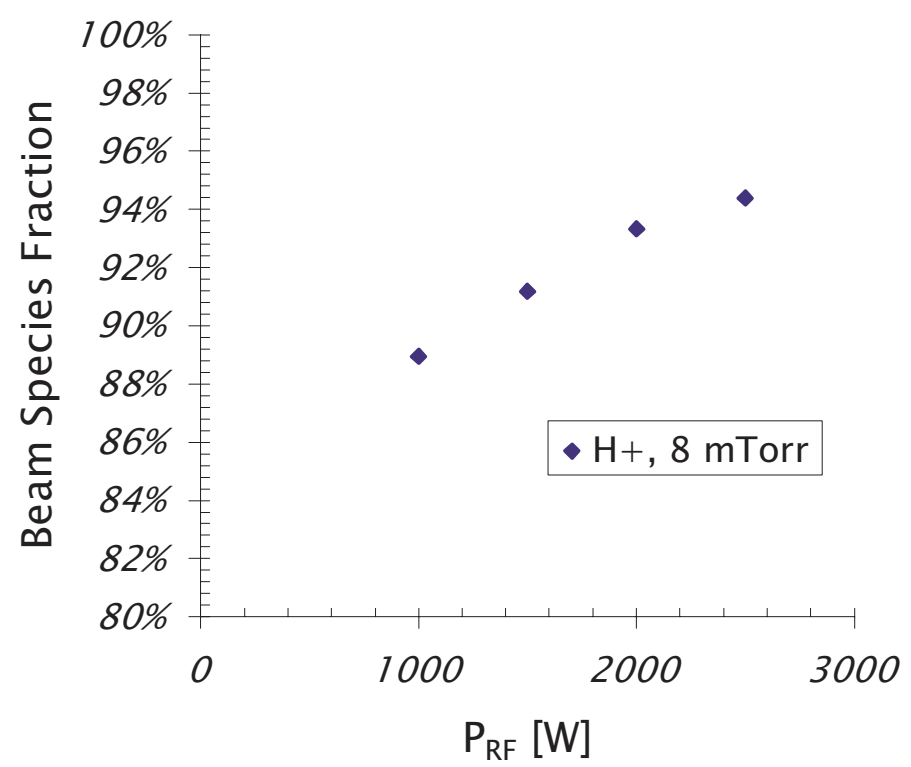

Figure 5. Atomic hydrogen species fraction of the extracted beam. 
The neutron generator was tested with a small, $1.3 \mathrm{~mm}$ in diameter extraction aperture. The extracted current at $1.5 \mathrm{~kW}$ and $80 \mathrm{kV}$ of acceleration voltage, was $\sim 2.0 \mathrm{~mA}$. The beam behavior is simulated using IGUN 7.005 ion extraction and beam transport code, see Figure 6. After two hours of operation at this power level, a $\sim 4 \mathrm{~mm}$ in diameter beam spot was noticed at the target surface. This result is in good agreement with the simulations.

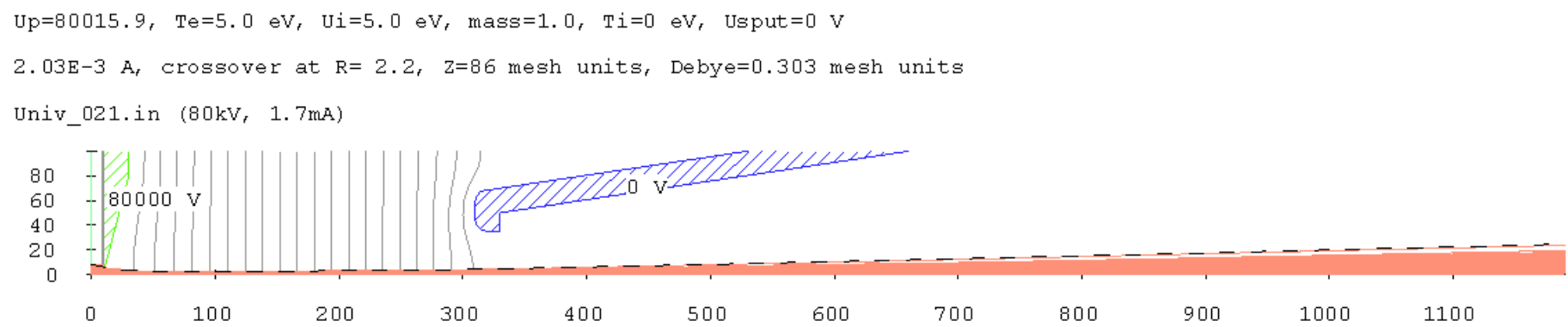

Figure 6. Simulation of $1.8 \mathrm{~mA}$ of deuterium beam at $80 \mathrm{kV}$ at the axial neutron generator extraction system. The simulation ends at the position of the target. The beam spot is $3.8 \mathrm{~mm}$ in diameter at the target.

The generator can be upgraded to $5 \mathrm{~mA}$ extracted beam current operation. By enlarging the extraction aperture to $2 \mathrm{~mm}$ in diameter, while keeping the chamfering of the plasma electrode, one will be able to extract $\sim 5 \mathrm{~mA}$ of beam at $80 \mathrm{kV}$ using $1.5 \mathrm{~kW}$ of discharge power. The simulation of the beam with $5 \mathrm{~mA}$ operation is shown in Figure 7.

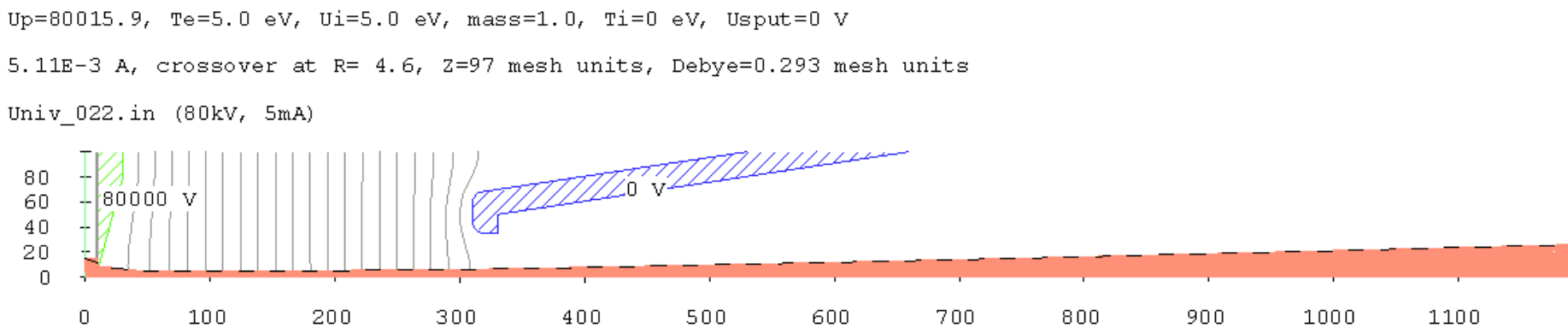

Figure 7. Simulation of $5 \mathrm{~mA}$ of deuterium beam at $80 \mathrm{kV}$ at the axial neutron generator extraction system.

The fabricated axial neutron generator is shown in the figure 8. The target assembly is shown separate from the vacuum vessel and the ion source. 


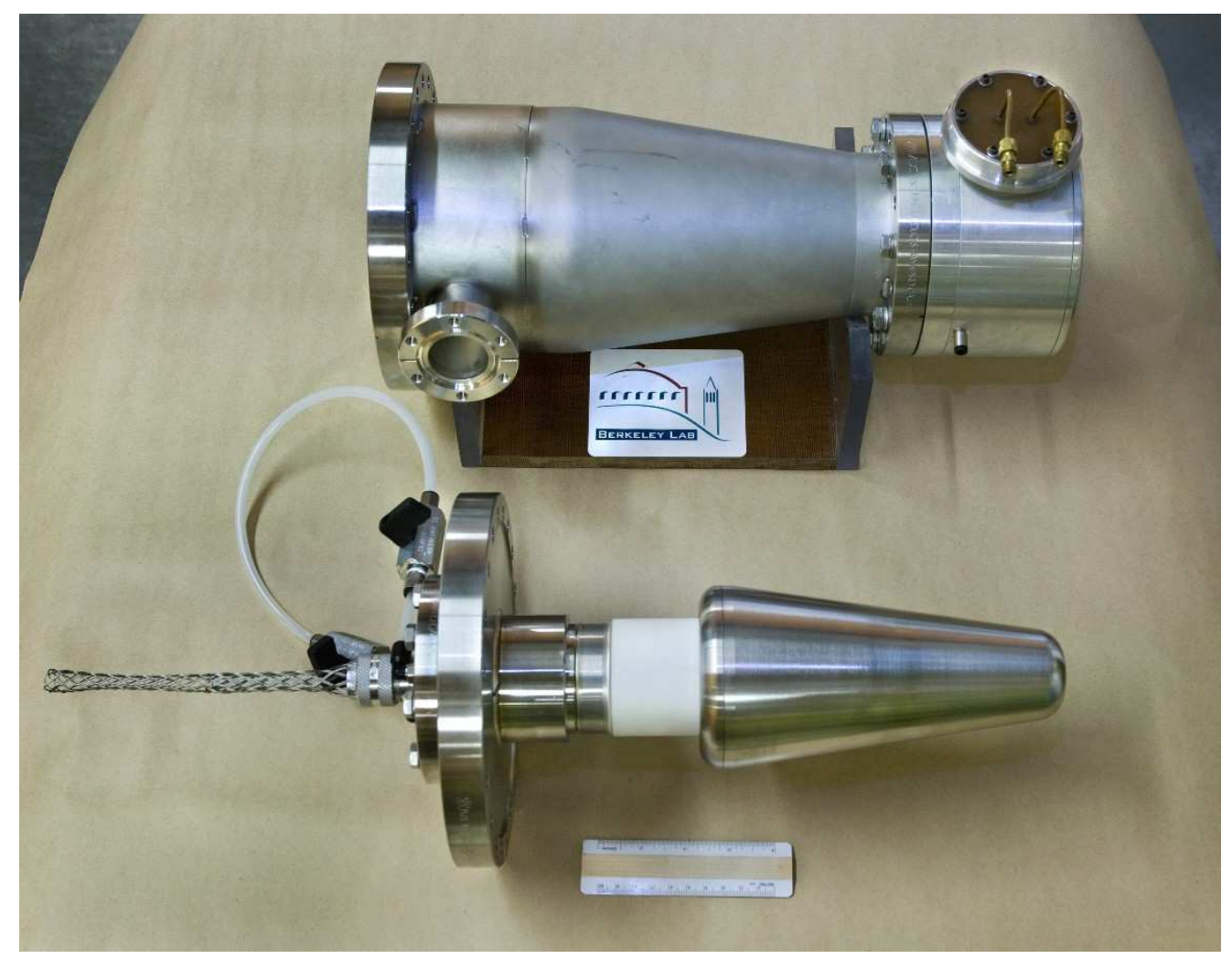

Figure 8. The axial neutron generator shown with target assembly separated from the vacuum vessel and the ion source. The generator is $50 \mathrm{~cm}$ in length.

Due to the relatively short high voltage insulator structure of the generator, the maximum operation voltage of the generator will be limited to $80 \mathrm{kV}$. At $80 \mathrm{kV}$ level, the generator is operating reliably without excessive high voltage breakdowns. The target is designed to operate at $1000 \mathrm{~W} / \mathrm{cm}^{2}$ power density level.

\section{Task 4: Neutron yield measurement}

The predicted neutron output of the generator at $80 \mathrm{kV}$ of acceleration energy and $5 \mathrm{~mA}$ of deuterium ion beam current would be about $\sim 10^{8} \mathrm{n} / \mathrm{s}$. Due to LBNL's safety regulation concerning shipping out activated radioactive materials, test of the device with deuterium gas can only performed after the device is transferred to the Department of Nuclear Engineering at UCB. Therefore, neutron yield was estimated from another available ion beam at LBNL.

A sectioned accelerator of another prototype neutron generator was used to accelerate the ions from a plasma generator with external antenna to a voltage of $80 \mathrm{kV}$. We used ${ }^{115} \mathrm{In}$ to measure the fast neutron flux and MCNP to calculate the neutron yield of the axial neutron generator. ${ }^{115}$ In foil activation is a well-known method for fast neutron measurement.[1] The D-D neutrons inside the polyethylene safety shielding are used to irradiate the Indium foil and produce ${ }^{115 \mathrm{~m}} \mathrm{In}$. To correct the back-scattered fast neutrons, a 
complete MCNP (Monte Carlo n-Particles) model is used to calculate the neutron flux to neutron yield conversion ratio. The angular dependent source neutron spectrum is used in the simulation.[2] The activity of the foil after irradiation is:

$$
A\left(t_{i}\right)=A_{o} e^{-\lambda t_{i}}+V N_{v} \sigma \Phi\left(1-e^{-\lambda t_{i}}\right)
$$

where $A_{o}$ is the activity before irradiation (zero for the foil used in this experiments), $l$ is the decay constant for In- $115 \mathrm{~m}$,

$t_{i}$ is the irradiation time,

$V$ is the volume of the In foil,

$N_{v}$ is the number density of In-115 atoms,

$s$ is the average (n,n') to the 1 st excited state cross section for In-115,

$F$ is the neutron flux.

$N_{v} \sigma \Phi$ per source neutron is calculated to be $6.79 \times 10^{-6}$ reactions $/ \mathrm{cm}^{3}$ per source neutron. The In-foil used in the experiment weighs $4.271 \mathrm{~g}$ with a volume of $0.584 \mathrm{~cm}^{3}$. The activity of the foil at the time of measurement is:

$$
A(t)=A\left(t_{i}\right) e^{-\lambda t}
$$

where $\mathrm{t}$ is the time after the irradiation.

The foil is irradiated for $5.25 \mathrm{hr}$ with an accelerating voltage of $80 \mathrm{kV}$ and a beam current of $\sim 1 \mathrm{~mA}$. In- 115 has an inelastic scattering cross section of $\sim 0.33 \mathrm{~b}$ to its 1 st excited state and In-115m has a half-life of 4.486 hours with $45.9 \%$ of its decay emitting a 336 $\mathrm{keV}$ gamma.[3] Therefore, the foil is left alone for 1 hour to allow the short half-life impurity activation products to decay. The measured activity of the foil is $36.39 \mathrm{~Bq} \pm$ $7.7 \%$ at the moment the gamma ray counting begins. Using the average cross section calculated from MCNP, we obtain a neutron yield of $2.1 \times 10^{7} \mathrm{n} / \mathrm{s} \pm 8 \%$. With a $5 \mathrm{~mA}$ current, the yield for the neutron generator is $\sim 10^{8} \mathrm{n} / \mathrm{s}$.

\section{Deliverables}

The deliverables include a fully functional axial, D-D neutron generator based on previously developed single beam axial neutron generator, vacuum pumping system with $150 \mathrm{l} / \mathrm{s}$ turbo molecular pump and a rotary vane roughing pump, high voltage power supply (Glassman 125 kV/5 mA), RF-amplifier (RFPP 20S) and RF-matching circuit.

\section{References}

[1] E.B. Nieschmidt, T. Saito, C.W. Barnes, H.-S. Bosch, and T.J. Murphy, "Calibration of the TFTR Neutron Activation System”, Rev. Sci. Instrum., Vol. 8, pp. 1715-7, (1988)

[2] J.D. Seagrave, E.R. Graves, S.J. Hipwood, C.J. McDole, "D(d,n)3He and T(d,n)4He Neutron Source Handbook", Los Alamos National Laboratory Report No. LAMS-2162, (1957) 
[3] A.B. Smith, S. Chiba, D.L. Smith, J.W. Meadows, P.T. Guenther, R.D. Lawson, and R.J. Howerton, "Evaluated Neutronic File for Indium", Argonne National Laboratory Report No. ANL/NDM-115, (1990)

\section{Presentations and Publications}

\section{Presentations}

1. IAEA Technical Meeting on Neutron Generators for Detection of Explosives and Illicit Materials, $13^{\text {th }}-16^{\text {th }}$ June 2005 , Vienna, Austria

2. Particle Accelerator Conference, PAC '05, Knoxville Tennessee, USA May 16 - 20, 2005, Invited

3. 18th International Conference on the Application of Accelerators in Research and Industry, October 10-15, 2004, Forth Worth, Texas

\section{Publications}

1. 18th International Conference on the Application of Accelerators in Research and Industry, October 10-15, 2004, Forth Worth, Texas Reijonen, Compact Neutron Generators For Medical, Homeland Security and Planetary Exploration, Invited. Proc. Particle Accelerator Conference '05, Knoxville TN, USA, May 16 - 20, 2005, LBNL-57599

2. J. Reijonen, F. Gicquel, S. K. Hahto, M. King, T- P Lou and K-N Leung, D-D Neutron Generator Development at LBNL, Applied Radiation and Isotopes, 63, 757 (2005), LBNL-56673

3. J. Reijonen, F. Gicquel, S. K. Hahto, K. N. Leung, T. G. Miller and P. K. Van Staagen, Advanced Neutron Generator Development at LBNL for Home Land Security Applications, abstract, CAARI 2004, 18th International Conference on the Application of Accelerators in Research and Industry, October 10-15, 2004, Forth Worth, Texas, LBNL-56672 Abstract. 